\title{
Religiões, Educação e Direitos Humanos: uma tríade possível?
}

\author{
Claris Tereza Tondello ${ }^{1}$ \\ Denise Silva Lipinsky² \\ Marcelo Siqueira Guilherme ${ }^{3}$
}

Resumo: $\mathrm{O}$ mundo atual nos apresenta uma ponta da evolução promovida pela humanidade: o avanço tecnológico, a moderna medicina, a facilidade de deslocamento, os gozos da alta tecnologia e, mesmo, o moderno vestuário que nos permite fazer uso da nanotecnologia. Aplaudimos o novo e a novidade; temos expectativas de que tudo o que é desenvolvido seja para o bem da humanidade. É notável o quanto desenvolvemos e, ao mesmo tempo, é difícil aceitar que ainda não avançamos quanto a coisas básicas: ainda temos as guerras - e nela usamos a moderna tecnologia - emperradas nos interesses mesquinhos; temos a mesma tecnologia à favor de dizimar populações inteiras; produzimos alimentos transgênicos para abastecer mercados, mas condenamos milhões a morrer de fome diariamente; dominamos o átomo para fins pacíficos e jogamos bombas sobre populações inteiras, condenando-as às dores físicas do câncer e da alma; somos, ao mesmo tempo, a natureza ambígua do anjo e do diabo. Mas em que cabem as religiões, a educação e os direitos humanos? Embora pareçam deslocadas, na verdade se apresentam muito mais próximas, pois são parte do universo humano. Este artigo tem por objetivo apresentar esses elementos, colocando as religiões, a educação e os direitos humanos vinculados diretamente ao seu sujeito principal - o homem -, alguns relatos, propostas e reflexões sobre a educação e a promoção dos direitos humanos na ambiência da sala de aula, além dela e o papel da tríade família-escola-educador para com os nossos educandos.

Palavras-chave: Promoção dos direitos humanos. Religiosidade. Educação. Alteridade. Vocação. Profissão.

\section{Religion, education and human rights: a possible triad?}

Abstract: The world today presents us with an edge of evolution, to which humanity has promoted: technological advancement, modern medicine, ease of movement, the joys of high technology and even modern clothing that allows us to make use of nanotechnology. We applaud the new, the novelty and expectations that everything developed is for the good of humanity. It is remarkable how much we have developed and at the same time it is difficult to accept that we have not yet advanced on the basic things: we still have wars - and we use modern technology - stuck in petty interests; we have the same technology in favor of decimating entire populations; we produce 
GM foods to fuel markets, but we condemn millions to starve daily; we dominate the atom for peaceful purposes and throw bombs on entire populations, condemning them to the physical pains of cancer and soul; we are at the same time the ambiguous nature of the angel and the devil. But where do religions, education and human rights fit? Although they seem to be displaced, they actually appear much closer: they are part of the human universe. This article aims to present these elements by placing religions, education and human rights directly linked to its main subject - the man -, some reports, proposals and reflections on education and the promotion of human rights in the classroom environment, beyond it and the role of the triad family - school - educator towards our students.

Keywords: Promotion of human rights. Religiosity. Education. Otherness. Vocation. Profession.

\section{Religiones, educación y derechos humanos: una tríada posible?}

Resumen: El mundo actual se nos presenta como punta de la evolución, donde la humanidad promovió el avance tecnológico, la medicina moderna, la facilidad de desplazamiento, el gozo de la alta tecnología e, incluso, el moderno vestuario que nos permite usar la nanotecnología. Aplaudimos lo nuevo, la novedad y esperamos que todo lo desarrollado sea para el bien de la humanidad. Es notable cuánto desarrollamos y, al mismo tiempo, es difícil aceptar que todavía no avanzamos en cosas básicas: aun tenemos guerras - y en ella usamos la moderna tecnología - fundadas en intereses minúsculos; tenemos la misma tecnología à favor de diezmar poblaciones enteras; producimos alimentos transgénicos para abastecer mercados, pero condenamos millones a morir de hambre diariamente; dominamos el átomo para fines pacíficos y lazamos bombas sobre poblaciones enteras, condenándolas a los dolores físicos del cáncer y del alma; somos, al mismo tiempo, la naturaleza ambigua del ángel y del diablo. Pero, ¿dónde caben las religiones, la educación y los derechos humanos? Aunque parezcan fuera de lugar, en verdad se presentan mucho más próximas, son parte del universo humano. Este artículo quiere presentar estos elementos colocando las religiones, la educación y los derechos humanos vinculados directamente a su sujeto principal - el hombre -, algunos relatos, propuestas y reflexiones sobre la educación y la promoción de los derechos humanos en el ambiente de la clase, más allá de ella y el papel del trío familia - escuela - educador para con nuestros educandos.

Palabras clave: Promoción de los derechos humanos. Religiosidad. Educación. Alteridad. Vocación. Profesión.

\section{A religiosidade católica, a educação e os direitos humanos: alguns casos recentes}

Para ilustração e reflexão deste tópico, serão relembrados alguns eventos:

- Pacaraima (Roraima), 18 de agosto de 2018: cidadãos brasileiros incendeiam barracas de refugiados e expulsam muitos de volta à Venezuela 
em uma tentativa de retaliação após o assalto e espancamento de um comerciante brasileiro por refugiados venezuelanos. Um incidente que, no fundo, revela outra grande faceta - a intolerância -, inflada com discursos prosélitos de afirmação de uma identidade e da inoperância do Estado em coibir essas ações.

- Vila da Penha, cidade do Rio de Janeiro, 14 de junho de 2015: a menina Kailane Campos, de 11 anos de idade, seguidora do Candomblé, é agredida e apedrejada na saída de um culto, com sua avó, em um dos bairros do norte da cidade carioca. Os autores são membros de uma igreja neopentecostal que, com palavras injuriosas, acusam-nas de seguidoras do diabo. A Arquidiocese de São Sebastião, lideranças religiosas do Candomblé, da Umbanda e de outros segmentos se manifestaram contra essa ação e lançaram nota de repúdio e de respeito à religiosidade das pessoas.

- Nova Iguaçu, Rio de Janeiro, 18 de agosto de 2017: também seguidora do Candomblé, a idosa Maria da Conceição Cerqueira da Silva, 65 anos é vítima de apedrejamento por sua vizinha por tê-la como "macumbeira" e, por esse motivo, deveu-se fazer "justiça".

- Brasília, Distrito Federal, 21 de março de 2016: ataque ao Centro Islâmico de Brasília (onde também se encontra a Mesquita). Jogam-se vários exemplares do Alcorão, utensílios e móveis, além de outros livros da doutrina islâmica fora do prédio. Não se soube, definitivamente, os autores do atentado que, por sorte, não deixou vítimas.

Situações como essas não deixam dúvidas quanto à dramaticidade, à crueza e à indiferença à vida humana e, ao mesmo tempo, pedem uma ação mais incisiva no combate à intolerância, na promoção do diálogo inter-religioso e, principalmente, no reconhecimento da vida humana em seus direitos plenos e sua eficácia.

É notável que, em tempos atuais, tenhamos presente na sociedade um novo ardor xenófobo, um discurso inflamado de altos representantes políticos que revivem um dramático e enfático discurso ultraconservador e do qual o estrangeiro é o "próximo alvo". Tais situações se presentificam nos Estados Unidos, na Europa, no Leste Asiático, na África e, com bastante preocupação, no ecúmeno Brasil.

Em tempos de radicalismo e de uma ortodoxia de pensamento, evidenciam-se tenazmente as vítimas desses mesmos paradoxos: o ser humano em suas mais manifestas expressões - a étnica, a religiosa, a política, a econômica, entre tantas outras. E é um tanto instigante quando determinada instituição tem a capacidade de promover - tanto teórica como praticamente - a responsabilidade da promoção do debate dos direitos humanos (nesse caso, todos os dedos se voltam à educação). 
Mas cabe a pergunta: estamos prontos, em nossa prática pedagógica e na cultura social de nossos educandos, para promover esse debate? Que práticas nos permitem conhecer, envolver, trabalhar e propor o diálogo entre as diversas formas de compreensão do ser humano em seus direitos, em sua plenitude e em defesa da vida humana. Em que sentido as escolas católicas podem contribuir para uma reflexão mais sucinta, rica e prática para a defesa dos direitos humanos?

É um caminho árduo e longo, que, com o empenho de cada educador, colocará em prática o sonho de ter a justiça social, o reconhecimento dos direitos e a dignidade da pessoa humana como instâncias práticas do nosso cotidiano e da nossa vivência; mas, para tanto, devemos fazer um pequeno histórico dessa situação.

Woods Jr. (2014) relata a importância da Igreja Católica na construção da sociedade ocidental em seus mais variados aspectos: na Economia, na Física e nas demais ciências, nas Artes, na Arquitetura, na Moral, na Filosofia, entre outras áreas da inserção e da ação humana. Aqui cabe um destaca especial: o desenvolvimento do direito internacional preconizados nos ideais de solidariedade, cooperação e fraternidade. Nesse âmbito, destacam-se os papéis do padre Francisco de Vitória, pela formulação de um direito internacional que prima, essencialmente, pela valorização do homem, e também do frade Bartolomeu de Las Casas, por aplicar, na prática, o reconhecimento da alteridade indígena e sua plena defesa na América espanhola, tendo por foco a questão da colonização e dos direitos dos hispânicos sobre os índios, tomando-os por inferiores, mas na defesa do jusnaturalismo de que todos os seres criados são iguais em seus direitos e dignidade, como mostra:

Tinham os espanhóis direito a possuir terras americanas em nome da Coroa? Quais eram suas obrigações em relação aos nativos? Tais assuntos levantavam, inevitavelmente, questões mais gerais e universais. Que conduta deviam os Estados obrigar-se a observar nas relações mútuas? Quais as circunstâncias em que se poderia considerar justa a guerra declarada por um Estado? Tratava-se obviamente de questões fundamentais para a teoria do moderno direito internacional. [...] Criado por Deus à sua imagem e semelhança e dotado de uma natureza racional, o homem possui uma dignidade da qual carecem todas as demais criaturas. Foi com base nisso que Vitória continuou a desenvolver a ideia de que, pela sua posição, o homem tem o direito de receber dos seres humanos, seus semelhantes, um tratamento que nenhuma outra criatura pode reivindicar (WOODS JR., 2014, p. 132).

Josaphat (2000) também demonstra que a defesa dos direitos humanos na América colonial colocou-se sempre à margem dos interesses das coroas espanhola e portuguesa, preocupadas em explorar o vil metal do que em, efetivamente, buscar a promoção e a defesa da integridade humana, tal como defendido 
pelo padre Francisco da Vitória. Isso fez com que frei Bartolomeu de Las Casas, dominicano e estabelecido no México, lutasse abertamente pela dignidade dos povos americanos diante do poderio da armada espanhola, dos interesses de uma casta de comerciantes que passava sobre qualquer vida humana. Percebe-se também que a Igreja Católica, na prática, combatia - mesmo com as condições de estar com o poder temporal da época - em favor das minorias e dos excluídos.

Para Dallari (2004), a discussão sobre os direitos humanos e a educação possui relevância na palavra "cidadania", a qual, entre os romanos, indicava a situação de uma pessoa quanto à sua condição política e sua capacidade de exercê-la. Como é notável, a sociedade romana era excludente - bem como a grega -, seletiva e dava direitos àqueles que eram dotados de dignidade, mas não àqueles aos quais nenhuma dignidade valia, ou seja, os escravos. Mesmo na classe dignitária do gozo da cidadania (ou os livres), distinguiam-se os patrícios - de famílias nobres e de respeito na sociedade, alguns oriundos dos fundadores de Roma dos plebeus - aos quais era possibilitado o acesso aos cargos públicos. Tal como a sociedade grega, os romanos:

Livres tinham a cidadania; eram, portanto, cidadãos, mas nem todos podiam ocupar os cargos políticos, com o de senador ou de magistrado, nem os mais altos cargos administrativos. Fazia-se uma distinção entre cidadania e cidadania ativa. Só os cidadãos ativam tinham o direito de participar das atividades políticas e de ocupar os mais altos postos da Administração Pública. Uma particularidade que deve ser ressaltada é que as mulheres não tinham a cidadania ativa, e por esse motivo nunca houve mulheres no Senado nem nas magistraturas romanas (DALLARI, 2004, p. 18, grifos do autor).

A Igreja Católica, por sua vez, tratando diretamente de difundir a fé cristã, era proscrita dentro da sociedade romana. Para os romanos, era a ideia de um monoteísmo, da fraternidade entre as diferentes pessoas - afinal, não havia distinção alguma entre as pessoas, que buscavam partilhar tudo em comum, acreditavam em um Deus único e praticavam seus cultos nas catacumbas romanas. Esse confronto de valores culturais acabaria por ter uma reação dos romanos ao levar muitos cristãos às arenas para serem devorados pelos leões. O que lhes causa pasmo é a presença de muitos patrícios romanos na fileira dos novos adeptos. O resto da história é conhecida.

Voltando à questão da educação, temos ainda o reporte de Woods Jr. (2014), ao apontar os monges como os promotores - na prática - da defesa dos direitos humanos. Com são Bento de Núrsia, pai do monarquismo ocidental, a prática dos valores e defesa da dignidade humana acabou por se efetivar com a defesa dos menores e dos nômades, figura bem clássica do início do monarquismo ocidental, no qual, com pequenas práticas, havia a tendência de vislumbrar o próprio Cristo em visita àquele mosteiro. Desse modo: 
São Bento também eliminou da existência do monge qualquer vestígio do seu passado no mundo, quer tivesse sido de grande riqueza ou de servidão e miséria, porque todos eram iguais em Cristo. $\mathrm{O}$ abade beneditino "não deve fazer distinção entre as pessoas do mosteiro" [...]. Um homem livre não deve ser preferido a outro nascido em servidão, a menos que haja alguma causa razoável. Porque, sejamos escravos ou livres, somos todos um em Cristo [...]. Deus não faz acepção de pessoas (WOODS JR., 2014, p. 27).

Em tempos atuais, os direitos humanos retornam à pauta do dia e, por muitas vezes, de forma negativa. Os editoriais das cadeias de televisão aberta exploram o tema de forma a superexpor as pessoas ou, de muitas formas, explorar o espetáculo humano, degenerativo e rebaixando a vida humana. Como dito, há a polêmica e o discurso voltado para a destruição dos direitos humanos ou, mesmo, de formadores de opinião, por meio da velha expressão da lei de Talião: "olho por olho, dente por dente". Não obstante, as redes sociais se colocaram como trincheiras onde o espaço da exposição das ideias, da liberdade de opinião e da defesa incondicional entre os direitistas versus esquerdistas extrapola todos os limites da sensibilidade, do bom senso e da responsabilidade para com a lisura da informação. Esse espaço, por sua vez, faz remonte ao passado romano: a arena na qual as opiniões eram amplamente destruídas, rechaçadas e expostas ao ridículo.

Por sua vez, as escolas se veem em um terrível embate: encontram-se no século XIX, com educadores do século XX e discentes no século XXI. A sociedade do atual século demanda outros debates, e muitos em âmbitos bastante polêmicos, como a discussão de gênero, o aborto, a pena capital, entre outras.

\section{Unidade na diversidade: quando o exemplo parte de cima}

A promoção da paz e da justiça social são promovidas pelas religiões como um todo. A Igreja Católica a assume em seu catecismo e nos documentos oficiais da igreja, bem como promove encontros ecumênicos com o intuito de um ponto comum - como as jornadas ecumênicas de Assis, acentuadas, principalmente, durante o pontificado de João Paulo II. Entretanto, a chamada "cultura da paz" ou "civilização da paz" não surgiu em seu pontificado: foram iniciadas com as invectivas de outro papa - João XXIII -, quando do Concílio Vaticano II. Um dos documentos conciliares - Unitatis Redintegratio - aborda o ecumenismo. Desde então, muitas iniciativas foram ricas em apresentar os pontos comuns às religiões em vista da promoção da vida humana, da defesa da obra da criação e da dignidade humana.

As escolas cristãs, por sua vez, tentam aproximar a mensagem cristã em meio a uma enorme pluralidade e diversidade cultural e religiosa dos discentes. Apesar da dura constatação de que há duas vertentes religiosas evidenciadas 
- a conservadora e a liberal - no âmbito católico, muitos oriundos do berço neopentecostal, um grande número de agnósticos ou simpatizantes de outros movimentos religiosos e daqueles que agitam as bandeiras de temas polêmicos e custosos, como o aborto, a homossexualidade, a pena de morte, a descriminalização das drogas, a defesa da propriedade privada, vê-se um amplo e largo campo de discussões ideológicas, permeadas de senso comum e de um lodaçal tremendo de pseudoutopias. Em flagrante, há uma grande variedade de camisas, das quais se pode fazer uso da que lhe convém. Isso, de certo modo, acaba por acirrar dois tipos de situação: aqueles que defendem as opiniões e aqueles que são totalmente contrários às opiniões.

Desse modo, temos em Arinze (2002, p. 19) que:

Nos dias atuais, o mundo não pode ficar indiferente ao aumento alarmante da quantidade de armas e do seu poder devastador. O compromisso com a não-proliferação de armas nucleares às vezes é vacilante. Não apenas governos, mas também grupos paramilitares, organizações terroristas e mesmo indivíduos parecem por vezes deixar-se seduzir pela tentação à violência.

As escolas católicas possuem um bom espaço para a promoção do diálogo consistente e, principalmente, para o reforço à dignidade humana, sem radicalismo ou pedância: há espaço para a vivência com outras expressões religiosas. Porém, ficam questões primordiais: como fazer para transformar em atitudes e vivências as práticas de tolerância, fraternidade, diálogo e escuta atenta em uma sociedade que prima pelo discurso violento, intolerante, indiferente, retrógrado e xenófobo, mesmo em escolas preocupadas com a quantidade, o currículo e a aplicação de ideologias mercadológicas? E quanto às famílias?

Há um caminho aberto ao diálogo ecumênico como há o encontro das religiões na cidade de Assis, o reconhecimento da perseguição às culturas e a todos os tipos de denúncias contra a vida humana emitidas pela Igreja Católica, pelo Conselho Mundial das Igrejas e pelos conselhos de competência reconhecida no Brasil, como a CNBB e o CONIC. Entretanto, falta um pouco de coragem às escolas - aproveitando a situação inequívoca de se posicionarem - em assumir o papel de promotoras da paz em seus muros físicos, eliminando os muros da ignorância e das ideologias quanto ao foco na vida humana. Sobre esse aspecto, para a ACAT (2001, p. 6-7):

Todos os dias, nos jornais, no rádio e na televisão, encontramos essas doutrinas, essas ideologias: já estamos saturados delas. Elas também estão presentes em nossa vida cotidiana, porém com um rosto, encarnadas em pessoas que tendemos a classificar precipitadamente segundo tal ou tal rótulo. Mais uma razão para conhecermos melhor o significado dessas palavras, sua origem, a evolução 
da realidade a que se referem. Há, contudo, um ponto em comum entre elas, sublinhado no texto de Jean-Louis Schlegel: designam doutrinas que estão "ante" a modernidade, para não dizer "defronte" dela ou "contra" ela.

Se o século XX trouxe-nos os desafios da interação entre as culturas, sendo que, pretensamente, houve a maturação de uma cultura hegemônica, difusa em seus valores, o século XXI nos traz o desafio de propor diálogos tolerantes, o reconhecimento da alteridade sobre a identidade e os desafios que extravasam a sociedade, chegando às salas de aula. Estamos em um mundo em desordem? Como propormos mudanças às pessoas onde imperam o caos, as ideologias parasitárias e a pretensa construção de uma cidadania sem o seu lócus e télos?

\section{Para além da sociedade líquida: direitos humanos reais para situa- ções humanas concretas}

Zygmunt Bauman (1925-2017) foi um dos mais brilhantes pensadores dos séculos XX e XXI. Judeu-polaco, sociólogo emigrado para o Reino Unido, perseguido em sua terra, tivera a brilhante oportunidade de analisar a sociedade em que vivera e a que assumira como sendo a sua nova casa. Oriundo de uma formação socialista e convivendo em uma sociedade assumidamente capitalista, pôde observar as transformações operadas nas sociedades a partir da mutabilidade do capitalismo. Essas análises se transformaram em um sem-número de publicações com a temática "líquida": modernidade líquida, vida líquida, amor líquido e as consequências advindas dessa liquidez na vida humana consubstanciadas em outros títulos, como capitalismo parasitário, vida a crédito, sociedade individualizada, identidade, globalização, mal-estar pós-moderno, cegueira moral, riqueza e pobreza, entre outros. Trata-se de uma obra extensa e reflexiva e jamais datada. Partindo da premissa da liquidez social, reflete-se um aspecto inegável em suas obras - a imersão e a submersão dos ismos - que transcendem espaços de integração (famílias e comunidades) para espalhar suas raízes no seio social, no qual:

Há uma condição de alerta permanente: perigos que se diz estarem à espreita bem ali na esquina, fluindo e vazando de acampamentos terroristas disfarçados em escolas e congregações religiosas islâmicas; de subúrbios habitados por imigrantes; de ruas perigosas infestadas de membros da subclasse; de "distritos turbulentos", incuravelmente contaminados pela violência; de áreas de acesso proibido em grandes cidades. Perigos representados por pedófilos e outros delinquentes sexuais à solta, mendigos agressivos, gangues juvenis sedentas de sangue, vagabundos e stalkers (os caminhantes furtivos). As razões para se ter medo são muitas. Já que é impossível calcular seu verdadeiro número e intensidade a partir 
da limitada perspectiva da experiência pessoal, acrescenta-se outra razão, possivelmente mais poderosa, para ter medo: não há como saber onde e quando as palavras de advertência irão se fazer carne (BAUMAN, 2007, p. 131).

A sociedade pós-moderna encontra seus desafios em integrar a pluralidade de opiniões, manifestações culturais, culturas, religiões em busca de um ponto comum. Talvez aí tenha residido a sua maior falha: tem sido uma sociedade de indiferentes, insensíveis e desconectados de um mundo real, concreto e clamorosamente precisando encontrar o seu rumo. Esses elementos, por sua vez, caem no universo escolar: a desintegração da pessoa humana que absorve - tal como uma esponja - às inúmeras ideologias e às manifestações de intolerância, seja no seio familiar, seja no convívio comunitário, aliadas aos inúmeros desvios de caráter, conduta ou mesmo oriundos das novas patologias (a série de Ts que carecem de uma maior profundidade acerca de sua origem e evolução), faz com que nos apresentem - constantemente - alunos que necessitam de uma experiência significante ao seu projeto de vida. A dissociação entre as crenças fundantes e as adquiridas criam inúmeros obstáculos ao convívio e ao diálogo em sala de aula. Nem mesmo as novas pedagogias conseguem explicar o fenômeno, colocando o sujeito como o centro, embora foquem no desenvolvimento das suas potencialidades intelectuais (e, em dias atuais, a resiliência), e não em seus aspectos subjetivos e psíquicos. Esse embate gera desgaste para os envolvidos diretamente (educadores e educandos) e para os coadjuvantes (escola e famílias). Encontrar o equilíbrio, possibilitar conexões vivenciais, reais, concretas é um dos desafios feitos diretamente na sala de aula e na experiência além da sala de aula. Nesse ponto, recorre-se a Boff (2003, p. 27) em uma reflexão que se coloca diante desse desafio:

Como construir uma plataforma comum sobre a qual todos possamos nos assentar e nos entender? Para viver como humanos, os homens e as mulheres precisam criar certos consensos, coordenar certas ações, coibir certas práticas e elaborar expectativas e projetos coletivos. Sempre houve tal fato desde os primórdios da construção das comunidades humanas.

Dada a situação: será que nos esquecemos de nos relacionarmos quando somos desafiados a manter a coletividade - embora diversa - e a conviver equitativamente? Em que ponto nos desumanizamos ou perdemos a compreensão do outro?

Nossos desafios, na atualidade, encontram-se em repropor uma nova forma de respeito à alteridade intersocial e intrassocial: observar a defesa da dignidade humana dentro da sociedade e fora da sociedade. Um caso claro: o assassinato do travesti Dandara dos Santos ocorrido no Ceará em 2017, amplamente filmado e tornado viral na internet. A insensibilidade diante do problema é tratada com des- 
dém por muitos educandos, reproduzindo o senso comum aplicado, infelizmente, em campanhas eleitorais e retomando questões espinhosas, como a redução da maioridade penal, a legalização do porte de armas (destinado aos cidadãos de bem), a descriminalização do aborto, o casamento homossexual, a discriminação das drogas, o fechamento das fronteiras e o expurgo de estrangeiros notoriamente de natureza xenófoba. Eis algumas das consequências da modernidade líquida.

Uma criança não aprende fora de um contexto específico; a família acaba por municiá-la, por "formar" a consciência e seu caráter. Por sua vez, a mesma família que pode tanger tanto para o conservadorismo como pelo liberalismo permite que a criança absorva tudo o que orbita ao seu redor, o que, em regra, acaba por se reproduzir diretamente na sala de aula. Algumas expressões são espantosas por se apresentarem incapazes de ouvir as opiniões contraditórias. Podemos pensar que são crianças oriundas dessa sociedade líquida na qual a desconexão entre o real e o ideal coloca o homem suspenso entre a borda e o abismo? E, em nosso caso, que realidade apresentamos para esses educandos?

Como apontado - o caso do travesti Dandara -, a questão dos direitos humanos divide opiniões e escancara o fosso de nosso abismo social. Temos uma sociedade dividida, narcisista, incapaz de reagir - ou, o mais fácil, terceirizar diante de situações especificamente absurdas. Porém, temos opiniões formadas sobre os direitos humanos: desde que não me prive o acesso aos meus direitos, tudo bem; mas, se envolvê-los, então calma! Entretanto, há muitos que farão a mais abjeta das afirmações: que se elimine todos os travestis! Nesse caso, o preconceito se enraíza não somente na perspectiva familiar, mas em pequenos casos, falas e, infelizmente, pelo viés da mídia, que extrapola o limite do bom senso. Isso, por sua vez, é determinante na prática da sala de aula: colocamos nossos preconceitos em stand-by ou os estimulamos a expô-los? Sabemos conduzir para uma reflexão acerca desses preconceitos - com fins de eliminá-los ou preferimos lavar as mãos? Até onde o professor-educador tem a capacidade de trabalhar tais situações sem a censura da escola? Quando as famílias - ao interpretarem livremente o que lhes foi repassado - acabam por validar os seus interesses, censurando a escola e o professor, elas fazem isso com que intuito?

São sinais evidentes de uma sociedade líquida, incapaz de refletir sobre as ações. Preparamos adultos para a indecisão ou para a conformidade? Preparamos pessoas para assumir o mundo ao seu redor ou criamos seres apáticos, acostumados ou acomodados às coisas que se põem à sociedade? De acordo com Brandão (2005, p. 26)

Para cada coisa que penso aparece um braço esticado dizendo "por aí não!”. Por onde, então? Será que o caminho para ser adulto é esse mesmo: o caminho da dúvida, da indecisão? Então eu fico igual àquele relógio da biblioteca, sem saber para que lado mexer os meus ponteiros. 
E, como em uma sociedade líquida, as questões mais preponderantes e reflexivas da vida humana acabam por ser polarizadas, extremadas ou ardorosamente defendidas - em seus interesses - como se fossem verdades absolutas. Direitos humanos, violência, o papel da mulher, a infância, a juventude, entre tantos outros, orbitam na esfera do imediatamente a resolver ou na esfera do discurso teórico. O enfoque é sempre o imediatismo, o confronto, o choque; não se chega a um ponto comum para a ação efetiva de mediar ou solucionar o problema. Nisso, Bauman (2007, p. 7) reforça:

\begin{abstract}
"Líquido-moderna" é uma sociedade em que as condições sob as quais agem seus membros mudam num tempo mais curto do que aquele necessário para a consolidação, em hábitos e rotinas, das formas de agir. A liquidez da vida e da sociedade se alimentam e se revigoram mutualmente. A vida líquida, assim como a sociedade líquido-moderna, não pode manter a forma ou permanecer em seu curso por muito tempo.
\end{abstract}

E também os valores dessa sociedade líquida fluem para a ambiência da sala de aula e, como reflexão, leva-nos a considerar duas coisas: de que forma a promoção dos direitos humanos perpassa a nossa prática cotidiana? Direitos humanos para humanizar pessoas ou direitos humanos para defender as pessoas?

\title{
Religiões, escolas e direitos humanos: equilibrar a equação, anali- sar as situações, conviver com a diversidade
}

A Igreja Católica, no último século, com mais ênfase nas últimas seis décadas, tem sido uma rica promotora do diálogo entre as religiões e, com os últimos quatro papas, da expressão de defesa da vida humana. Recentemente, o papa Francisco tem alertado sobre a causa dos refugiados do Oriente Médio e da África, acolhendo-os na cidade do Vaticano. Também tem se associado à defesa da vida, da denúncia ao vilipêndio da vida humana em suas mais variadas formas, alinhando-se com outros representantes das mais variadas religiões. $\mathrm{O}$ arcebispo anglicano emérito Desmond Tutu publicou o livro com o Dalai Lama acerca das muitas questões da sociedade pós-moderna, em uma reflexão dialético-espiritual rica, trazendo a dimensão da finitude humana diante da grandeza do infinito na vida humana (LAMA; TUTU; ABRAMS, 2017). Também Frei Betto nos traz profundas reflexões no campo da práxis ativa do cristão, que, saindo de sua "fortaleza dogmática", vai ao encontro do outro, dialoga, reflete, compromete-se em promover a alteridade e trabalha pelo bem comum, em obra conjunta com o jornalista Heródoto Barbeiro (BETTO; BARBEIRO, 2017). São reflexões ricas, fundamentadas na realidade e que versam diretamente com a questão dos direitos humanos. 
François-Marie Arouet, o filósofo Voltaire, notório defensor da liberdade humana e um verdadeiro "língua solta" contrário à fé religiosa, satírico e, não menos importante realçar, autor de uma obra que, ao mesmo tempo, denuncia a relação de extremismo religioso e a condenação de um comerciante de Toulouse - Jean Calas - chamada de "Tratado sobre a tolerância", pronunciou uma oração que, nos tempos de hoje, é atual e uma forma de denúncia. Em suma, é um primeiro tratado sobre a defesa dos direitos humanos em plena era do domínio da razão, uma das mais aterradoras épocas da história humana.

Assim:

Não é mais, portanto, aos homens que me dirijo, é a ti, Deus de todos os seres, de todos os mundos e de todos os tempos. Se é permitido a fracas criaturas perdidas na imensidão e imperceptíveis para o resto do universo ousar te pedir alguma coisa, a ti que deste tudo, a ti cujos decretos imutáveis são eternos, digna-te olhar com piedade os erros ligados a nossa natureza; que esses erros não sejam causa de nossas calamidades. Tu não nos deste um coração para nos odiarmos e mãos para nos degolarmos; faz com que nos ajudemos mutuamente a suportar o fardo de uma vida penosa e passageira; que as pequenas diferenças entre os trajes que cobrem nossos débeis corpos, entre todas as línguas insuficientes, entre todos nossos costumes ridículas, entre todas nossas leis imperfeitas, entre todas nossas opiniões insensatas, entre todas nossas condições tão desproporcionais a nosso olhos e tão iguais diante de ti: que todas essas nuances que distinguem os átomos chamados homens não sejam sinais de ódio e de perseguição; que aqueles que acendem velas em pleno meio-dia para te celebrar suportem aqueles que se contentam com a luz do teu sol; que aqueles que cobrem suas roupas de baixo por uma capa branca para dizer que é preciso te amar não detestem aqueles que dizem a mesma coisa sob um manto de lã negra; que seja igual te adorar num dialeto formado de uma antiga língua ou num dialeto mais recente; que aqueles cujo traje é tingido de vermelho ou de violeta, que dominam uma pequena parcela de um pequeno acúmulo de barro deste mundo e que possuem alguns fragmentos arredondados de certo metal, usufruam sem orgulho daquilo que eles chamam grandeza e riqueza, e que os outros os vejam sem inveja, pois tu sabes que não há nessas vaidades do que invejam nem do que se orgulhar.

Que todos os homens possam se lembrar que são irmãos! Que tenham verdadeiro horror da tirania exercida nas almas, como têm como execrável o banditismo que destrói pela força o fruto do trabalho e da indústria pacífica! Se os flagelos da guerra são inevitáveis, não nos odiemos, não nos dilaceremos uns aos outros no seio da paz e empreguemos o instante de nossa existência em abençoar igualmente em mil línguas diferentes, desde o Sião até a Califórnia, tua bondade que nos concedeu esse instante (VOLTAIRE, 2017, p. 129-130). 
Voltaire antecipa - em alguns séculos - o que surgiria no século XX e se presentifica no século XXI: dialogar para a promoção humana, agir para que todos sejam reconhecidos como iguais. E, em um desafio angustiante: como fazê-lo no microcosmo da sala de aula?

O século XXI nos apresenta um desafio para as escolas: captar o maior número de alunos e formá-los; para as famílias: a de "encaixar" os filhos na escola que melhor possa complementar o seu trabalho doméstico; para os professores-educadores: alunos muito diferentes, com percepções de mundo diferentes e, em muitos casos, feitos à imagem e semelhança de seus progenitores. Na esteia do neoliberalismo e das muitas ideologias pós-modernas, há um desafio para o educador em trabalhar a temática, os conteúdos, o relacionamento e, ainda mais evidenciado, a questão religiosa na vida do educando. O século XX também acirrou a questão religiosa, uma diversidade de ofertas soteriológicas, a ortodoxia ferrenha que divide povos, culturas, opiniões e, claro, não fica de fora da sala de aula. É bem real que se tem educandos nesse viés do século XXI, muitos nascidos nesse século, que o fenômeno religioso se manifesta no corpo discente.

As religiões buscam defender elementos, como a promoção do bem, a defesa da verdade e dos valores presentes em seu bojo. Entretanto, tem-se - em cada religião - muitos pontos de vista que, por sua vez, criam segmentos dentro das religiões. Cada vez mais fiéis acabam por seguir uma linha " $x$ ", outros, a linha " $y$ ", outros, a linha " $z$ ", outros que preferem somente frequentar sem aderir, outros assumem a ideia de uma pluralidade vivencial e que lhes permitem ser espiritualistas. O papel da religião, em opiniões expressas por discentes, nada mais é do que uma formalidade ou de absoluto descaso. Há muitos que dirão ser céticos, ateus ou mesmo agnósticos.

Tratar dos direitos humanos caberia "somente" às aulas de ensino religioso, filosofia e sociologia, certo? Nada mais errôneo: é âmbito de todas as ciências, discutida em todas as disciplinas e com expressa condução dos educadores e postura assumida pelas escolas. É necessário que tenhamos mais educadores aptos, não somente a conhecer a sua área de conhecimento, mas a difundir a postura proativa de um educando apto a transformar a sua realidade. Muito se expõe sobre a escola sem partido, sobre a discussão a respeito de gênero, feminicídio, entre tantos outros temas caros; é preciso fazê-lo em aberta defesa do ser humano, dotado de uma vida, imerso em uma cultura, agente de sua história e membro social, antes do que o adjetivo que o precede.

E aqui cabem alguns pontos que esses autores defendem:

1) Recuperar o sentido da escola como formadora e humanizadora, e não somente uma instância no processo de educação de um indivíduo. Precisa escolher entre o seu papel central de formadora-humanizadora ou de ser mais uma no chamado mercado educacional ${ }^{4}$. 
2) A família como cooperadora e coformadora de um sujeito emancipado, ecúmeno e defensor da vida humana. Saber "desligar-se" da opinião mundana, promover experiências vivenciais sobre as dimensões humanas, e não a transferir (terceirizá-la) aos cuidados da escola.

3) Educadores promotores do papel transformador que lhes é devido, não ideológico, emancipador e abertamente capaz de acolher as diferenças, desmontar os falsos argumentos e propiciar-lhes uma reflexão acerca da vida humana. Há valores que são defendidos e que, por sua vez, acabam por se refletir sobre os educandos.

4) Demonstrar e incentivar atitudes que impactem na vida do educando. Há muitos que chegam cheios de dificuldades, protegidos por uma redoma invisível pelas famílias, sem capacidade de conhecer a realidade daqueles que são marginais à sociedade. Como um exemplo rico e edificante, há projetos maristas, como a Missão Marista de Solidariedade, que agregam alunos não católicos, mas ativos, na promoção do bem, da alteridade, sensíveis à realidade ao seu redor. Também é uma oportunidade de interação entre os educandos, em partilhar experiências de vida e, em muitos casos, despertar a profissão futura que abraçarão. O mais importante: desperta-lhes a vocação para a vida.

5) Investir - no caso das escolas católicas - nas equipes pastorais e colocá-las no centro da vida escolar, pois o quanto as equipes pastorais foram postas em escanteio e, desse modo, vistas com olhos da desconfiança. Esquecem-se de que o administrativo, o pedagógico e o pastoral caminham em conjunto, formam, refletem, qualificam e permitem ao jovem e ao colaborador sentirem-se escola e educadores. Não resumir a Pastoral a uma pessoa (personalização), a um evento enfadonho, a uma equipe (ou a um único ser) que somente reza e, em última instância, possa salvar a escola: colaborar mais do que comprometer é um dos pilares de uma escola católica; sem ela, o papel se resume em ser, somente, uma escola ou mais uma escola. A Pastoral desperta o nascimento de lideranças proativas, edificantes, que promovem sem fazer propagandas mercadológicas. Nesse ponto, as escolas católicas impactam diretamente na vida dos educandos a ponto de - após tornarem-se chefes de família - colocarem seus filhos na escola onde aprenderam a lidar e ver o mundo de outra forma.

Educadores comprometidos, não ideologicamente com a profissão de fé que fazem, mas com a causa do ser humano, devem ser modelos aos demais colegas. Sabe-se que há dentro da classe docente um pecado capital - a inveja - que impede que nos vejamos como ativos sujeitos do processo de educação e formação do educando. Quando há uma defesa in extremis de uma ideologia religiosa, não educamos, mas formamos sectários ou, quiçá, um extremista religioso. É preciso ver a cultura local como um microcosmo do vasto universo, 
rico em pluralidades, e dialogar com essas culturas e, antes, com os seres que as compõem. É fato que se trata de algo importante a ser discutido, mas não tão importante ao interesse geral.

Experiências básicas, fortuitas e oportunas enriquecem a nossa prática experiencial-vivencial que auxilia na formação do educando. Não fugir dos temas mais duros e que estão na esfera do humano, invertendo a questão com outra questão ("o que o leva a afirmar isso?, "qual é a sua posição sobre esse tema proposto?”, entre outros), coloca o aluno como o centro da discussão, permitindo-nos explorar os sofismos e as impressões erroneamente construídas e que, por sua vez, são facilmente reproduzidas sem reflexão. Não temos que nos esquivar desses temas, mas enfrentá-los de forma enfática, posicionando-se acerca da defesa - antes - do ser humano. Como dito, antes dos adjetivos, a pessoa se apresenta.

Não cabe somente às escolas católicas essa defesa, essa proposição, essa visão: convidamos todos a participar, a se engajarem, a cerrar fileiras na defesa da vida, mesmo em questões que expõem nossa "nudez intelectual" e nos agridem, mas não nos põem em frente a um tribunal de isentos, mas a pessoas que necessariamente nos têm como modelos de virtude ou de desgraça. Assim, impactamos diretamente a vida dos educandos.

E, como não poderíamos deixar de recorrer à licença poética, usamos de uma frase de Renato Russo: "e você de que lado está?”.

\section{Considerações finais: testemunho, defesa da dignidade humana e reconhecimento da alteridade}

Diante do exposto e de que não há como dissociar a questão educacional do mundo da vida, temos a certeza de que o nosso papel de mudança e transformação dos corações e almas dos educandos volta como o centro de nossa missão: educar é uma maiêutica constante, o desafio de transformar e emancipar educandos poderia ser comparada - em dias atuais - hercúlea. Temos a dimensão dos desafios e sabemos que diariamente eles se constituem e nos propõem uma ação. É impossível passarmos incólumes em nossa vocação (aqui não somente profissão, pois seria o passo seguinte dessa vocação madura), mesmo que os desafios impostos e surgidos nos colocam em um grau de impotência, mas nunca de inoperância. Assumimos a nossa profissão de fé cristã, espelhamo-nos em Jesus Cristo, mestre, senhor e modelo, temos à nossa frente um universo que se apresenta cheio de questionamentos, posturas prontas e desafiantes propósitos - os educandos -, e a garantia de que nosso trabalho só terá resultado em um futuro.

Sabemos que a humanidade se constitui de homens que possuem o livre-arbítrio, os quais estão inseridos em culturas diversas, exprimem convicções 
diversas e questionamentos acerca de um mesmo objetivo: o que nos faz estarmos aqui? Por que aceitar isso, e não aquilo? Por que da existência do mal? São perguntas que há milênios são proferidas, muitas das quais não se obtém uma resposta significativamente suficiente. Mas há práticas! Há ações! Há pessoas que se puseram em campo, foram em busca de realizar não o seu ideal próprio, mas preparar o campo para outros semeadores, outros agricultores e outros promotores, como Albert Schweitzer (apud ABRAMS, 2011, p. 35):

\begin{abstract}
Há muitos anos participei de uma discussão acerca do problema da educação internacional. Depois de vários especialistas apresentarem suas complicadas teorias, o velho diretor de determinada escola levantou-se e disse em voz baixa: "Há apenas um sistema de educação: a educação pelo amor e pelo exemplo próprio.” Ele estava certo. O que é verdade para a educação é verdade também para o problema atual dos refugiados. Com amor e por meio de nosso exemplo exemplo no sentido de sacrifício -, ele pode ser solucionado.
\end{abstract}

A educação só pode ser feita como um ato de amor; promover a solidariedade e os valores da pessoa humana somente pode fazê-lo por meio de amor. $\mathrm{O}$ reconhecimento da alteridade que promove a dignidade humana rompe os adjetivos, dá valor ao que a pessoa é, não se atém aos “ismos", tampouco observa o ser humano como uma pessoa digna de pena; pelo contrário, faz reconhecer a estatura e a nobreza do ser que ali se apresenta. Por sua vez, faz-se necessário em nossas práticas educativas promover os valores humanos e, mais ainda, em se tratando das escolas confessionais, tê-las como um compromisso.

Educadores capazes de dialogar e promover incitam escolas a assumir o seu papel de formação integral e, que por sua vez, podem exigir das famílias o seu aspecto mais significativo: formar o caráter de sua prole. Basta lembrarmos as palavras de Albert Schweitzer que, mesmo com os seus prêmios, seu reconhecimento, sua estatura intelectual, preferiu abandonar tudo e ir ao Gabão para cuidar daqueles aos quais lhes eram negados a dignidade e os direitos. Exemplo digno ou utopia em nossos dias?

As religiões têm a sua preocupação e seu lugar de responsabilidade nos dias atuais, e, mesmo com tantos escândalos, há os que permitem passar sobre todo o senso comum na promoção da alteridade. Não poderiam ser consideradas religiões se não colocam o ser humano no papel central de transformação e se Deus não conferir os cuidados por esse mundo criado aos animais senão ao próprio ser humano.

O cuidado com a natureza também se estende ao cuidado com a natureza humana; somos nós, educadores, que temos a missão de ressaltar e reconhecer a dignidade humana como ela é - isenta dos adjetivos, das bandeiras ideológicas, do sectarismo - como um ser aberto ao mundo, reconhecido em seus direitos e promovido em sua dignidade. 
Recebido em: 11/09/2018

Revisado pelo autor em: 05/10/2018

Aceito para publicação em: 26/10/2018

\section{Notas}

${ }^{1}$ Pedagoga, orientadora educacional, coordenadora de Pastoral no Colégio Claretiano Stella Maris em Taguatinga. Pós-graduada em Ciências da Religião pela Universidade Católica de Brasília (UCB). Especialista em História do Cristianismo Antigo pela Universidade de Brasília (UnB). Especialista em Neuropsicopedagogia pela Faculdade de Tecnologia de Palmas. Analista junguiana pelo Instituto Junguiano de Ensino e Pesquisa (IJEP). Estudiosa da Psicologia Sistêmica. E-mail: profclaris@gmail.com

2 Pedagoga e professora da Educação Básica (Fundamental I) na rede pública de ensino da cidade de Curitiba (PR). Atriz amadora com trabalhos realizados com a Prefeitura Municipal de Curitiba em atividades pedagógico-literárias em diversos estabelecimentos culturais da cidade. Atualmente, aborda estudos em pedagogia inclusiva, atentando aos estudos sobre autismo, transtornos e déficits cognitivos. E-mail: deniselipi@gmail.com

3 Educador, filósofo e professor de Filosofia e Ciências da Religião por escola católica. Palestrante, estudioso, catequista e apaixonado por estudos. Tem publicação na área de política social acerca do orçamento para educação, exposição de artigos em seminários locais e internacional. É músico amador, leitor e cinéfilo inveterado. Tem licenciatura em Filosofia pela Universidade Federal do Espírito Santo (UFES). Especialista em Filosofia Política e Social pela UFES. Especialista em História do Cristianismo Antigo pela Universidade de Brasília (UnB) e em Ensino Religioso (Ciências da Religião) pela Universidade Católica de Brasília (UCB). Mestre em Política Social pela UnB. É pesquisador e vem aprofundando os estudos sobre a educação (BNCC e reformas do Ensino Médio e Superior) e suas consequências e seus impactos nas gerações futuras no Brasil. E-mail: msmarcelosguilherme2017@gmail.com

4 É claro que aqui não criticamos as escolas que nos acolhem, mas calcamos no princípio ideal que move a sua existência enquanto escola, em razão de seus princípios fundantes - no caso das escolas católicas, a base de seus pais/mães fundadores sempre fundamentada no Evangelho.

\section{Referências}

ABRAMS, Irwin. Heróis da paz. São Paulo: Autêntica; Belo Horizonte: Gutenberg, 2011.

ACAT - Ação dos Cristãos para Abolição da Tortura. Fundamentalismos integrismos: uma ameaça aos direitos humanos. São Paulo: Paulinas, 2001.

ARINZE, Cardeal Francis. Religiões para a paz. São Paulo: Pensamento-Cultrix, 2001.

BAUMAN, Zygmunt. Vida líquida. Rio de Janeiro: Jorge Zahar-Editor, 2007.

BETTO, Frei; BARBEIRO, Heródoto. O budista e o cristão: um diálogo pertinente. São Paulo: Fontanar/Schwarcz, 2017. 
BOFF, Leonardo. Ethos mundial: um consenso mínimo entre os humanos. Rio de Janeiro: Ed. Sextante, 2003.

BRANDÃO, Sérgio Vieira. A ciência das diferenças. A diversidade cultural no ambiente escolar. São Paulo: Paulinas, 2005.

DALLARI, Dalmo de Abreu. Direitos humanos e cidadania. São Paulo: Ed. Moderna, 2004.

JOSAPHAT, Frei Carlos. Las Casas: todos os direitos para todos. São Paulo: Loyola, 2000.

LAMA, Dalai; TUTU, Desmond; ABRAMS, Douglas. Contentamento: o segredo para a felicidade plena e duradoura. São Paulo: Principium/Globo, 2017.

VOLTAIRE. Tratado sobre a tolerância. São Paulo: Lafonte, 2017.

WOODS JR., Thomas. Como a Igreja Católica construiu a civilização ocidental. São Paulo: Editora Quadrante, 2014. 